\title{
Editoras de periódicos predadores: um perigo na divulgação de resultados de pesquisa no Brasil e no mundo
}

\author{
Publishers of predatory journals: A danger in the dissemination \\ of research results in Brazil and in the world
}

\author{
Anselmo Gomes de OLIVEIRA; \\ Dâmaris SILVEIRA \\ Editores
}

Desde os últimos 30 anos, além dos periódicos científicos impressos e de acesso restrito, que são mantidos por meio de assinaturas ou por sociedades científicas, surgiram outros periódicos, impressos e/ou online, em sua grande maioria de acesso livre, que para sua manutenção cobram dos autores interessados na publicação. Assim, o autor é solicitado a pagar taxa para submissão de artigos, taxas de editoração, taxas para manutenção on line, taxas para visualização completa do artigo on line, ou, as mais comuns, taxas para a publicação, os quais na maioria das vezes são de acervo aberto. Ou seja, instituições de pesquisa do mundo todo ou devem pagar taxas anuais para ter acesso aos artigos científicos, muitas vezes de autoria de seus próprios pesquisadores, ou pela publicação dos artigos de seus pesquisadores.

No Brasil a situação não é diferente. A grande maioria da produção científica é realizada dentro de Instituições Públicas de ensino ou pesquisa e, portanto, financiadas com recursos públicos, da própria Instituição ou de Agências de Fomento, também públicas. Os processos de avaliação dos artigos para publicação também são, em sua grande maioria, realizados por profissionais de instituições públicas. Assim, quando o pesquisador submete seu manuscrito, contendo resultados gerados com recursos públicos, em muitos casos, deve transferir os direitos autorais para a editora do periódico, geralmente do setor privado. Desta forma, as Instituições de ensino ou de pesquisa são obrigadas a pagar vultosas quantias para ter acesso aos resultados que foram gerados, avaliados por seus próprios pesquisadores e financiados com recursos públicos (1).

Nesse contexto, a Coordenação de Aperfeiçoamento de Pessoal de Nivel Superior (Capes), tem investido cerca de quarenta e dois milhões de dólares por ano para disponibilizar, aos pesquisadores brasileiros, o acesso a artigos de cerca de 37.000 periódicos nacionais e internacionais, bem como a diversas bases de dados contendo referências e resumos de trabalhos acadêmicos e científicos, normas técnicas, patentes, teses e dissertações, entre outros tipos de materiais em todas as áreas do conhecimento (2).

Em contraposição a esse modelo editorial, pesquisadores e instituições de ensino e pesquisa defensores do livre acesso ao conteúdo dos artigos científicos, criaram os chamados Open Access Journals. A Open Access Iniciative surgiu na Europa e nos Estados Unidos nos anos 90. No inicio do movimento, os periódicos que utilizavam esse modelo de publicação ajudaram a melhorar a publicação científica, reduzindo custos (autores e instituições são responsáveis por todos os custos editoriais) e permitindo o livre acesso aos artigos publicados (3).

Contudo, nos últimos anos, com os periódicos de livre acesso, surgiram também as Editoras predatórias. Os periódicos geralmente apresentam títulos muito abrangentes, ou muito semelhantes a títulos de periódicos renomados, publicados por Editoras idôneas, com o único objetivo de explorar financeiramente o modelo dos periódicos de acesso livre. Essas editoras não mantêm um mínimo de critérios na avaliação dos artigos, e geralmente prometem a publicação em tempo extremamente curto para considerar qualquer procedimento ético editorial na avaliação dos artigos (4). Assim, atualmente, a comunidade científica também deve ter a habilidade de reconhecer a fraude editorial.

Para identificar editoras predatórias, Jeffrey Beall, professor associado e bibliotecário da Universidade do Colorado, Denver, traçou um conjunto de mais de 40 
critérios para a identificação de Editoras predatórias (5). Embora muito esforço esteja sendo dispendido para inibir essa prática, essas editoras e seus periódicos têm aumentado exponencialmente nos últimos anos.

$\mathrm{Na}$ última atualização da lista de Beall, em 11/ Dez/2016, foram identificados cerca de 1100 Editoras e 1300 periódicos individuais potencialmente predatórios $(6,7)$. O número de editoras predatórias saltou de 18 em 2011, para cerca de 1100 em dezembro de 2016 e os títulos de periódicos predatórios, de $126 \mathrm{em}$ 2013, aumentou para cerca de 1300 em dezembro de $2016(6,7)$.

Pressão para aumentar o número de publicação, exigência, por programas de pós-graduação, de ao menos um artigo publicado para que o estudante possa defender sua tese ou dissertação, são alguns fatores envolvidos na decisão por submissão de artigos a essas editoras e seus periódicos. Mas a massificação numérica das publicações em detrimento da qualidade das pesquisas científicas, certamente contribui muito para esse cenário de expansão dessas editoras e periódicos. Além disso, lamentavelmente, nem todos pesquisadores estão preparados material (infraestrutura, financiamento, den- tre outros) ou intelectualmente para a realização pesquisas de médio-alto impacto.

Finalmente queremos ressaltar que Infarma-Ciências Farmacêuticas é um periódico impresso e on line, de publicação gratuita, sem cobrança de taxas para publicação, mantido pelo Conselho Federal de Farmácia e cujo escopo envolve toda a área das Ciências Farmacêuticas. Possui uma política de avaliação por pares totalmente transparente e independente, aplicável indistintamente e sem exceções, a todo manuscrito recebido por nosso sistema. O autor pode acompanhar todas as etapas do proceso editorial. Ainda, a publicação dos artigos está condicionada a não existência de pendências quanto aos questionamentos dos revisores e a decisão sobre a finalização da conclusão do processo de avaliação e de publicação ou rejeição dos artigos é de competência exclusiva dos editores de Infarma-Ciências Farmacêuticas.

Nesse último número de 2016, agradecemos a todos os assessores $A d H o c$ que colaboraram com o periódico durante esse ano e aos autores dos artigos que nos honraram com suas indipensáveis colaborações. Esperamos continuar contando com sua colaboração no ano que se inicia.

\section{REFERÊNCIAS}

1. Blog do pós-graduando. Cuidado com as armadilhas dos periódicos predatórios (http://posgraduando.com/cuidado-com-as-armadilhas-dos-periodicos-predatorios/) 2014 [

2. CAPES. Periódicos Capes. Histórico (http://www-periodicos-capes-gov-br.ez54.periodicos.capes.gov.br/index. php?option=com_pcontent\&view=pcontent\&alias=histo rico\&Itemid=100). 2016.

3. Yiotis K. The open access initiative: A new paradigm for scholarly communications. Information technology and libraries. 2005;24(4):157-62.

4. Beall J. Predatory publishers are corrupting open access. Nature. 2012;489(7415):179.

5. Beall J. Criteria for determining predatory open-access publishers. Scholarly open access https://scholarlyoafileswordpresscom/2015/01/criteria-2015pdf wordpress com/2015/01/criteria-2015pdf,(accessed2015-02-14). 2015.

6. Beall J. List of Predatory open access Publishers-Jan 2016. Disponivel em: https://scholarlyoa.com/2016/01/05/ bealls-list-of-predatory-publishers-2016/2016 [

7. Beall J. Beall, J. List of standalone journals. Disponivel em: https://scholarlyoa.com/individual-journals/ 2016 [ 